\title{
Designing a customized clinical practice guideline regarding antibiotic prophylaxis for Iranian general dentists
}

\author{
Najmeh Savadi ${ }^{1 *}$, Omid Barati ${ }^{2}$, Hossein Mirhadi ${ }^{3}$ and Ali Golkari ${ }^{1}$
}

\begin{abstract}
Background: Clinical practice guidelines produced by developed countries seemed to be not completely feasible for developing countries due to their different local context. In this study, we designed a customized guideline about antibiotic prophylaxis before dental procedures for Iranian general dentists.

Methods: This study was conducted of two parts, including a qualitative part and a cross-sectional analytic part. A multidisciplinary team searched for related guidelines and other documents, selected the most updated and high quality ones, customized their recommendations based on available antibiotics in Iran, prepared a draft adapted guideline and summarized its recommendations in 3 flowcharts. An expert panel (20 specialists of four Iranian dental universities) participated in a consensus process, afterwards to determine the relevance and clarity of the flowcharts and their items. Then the Content Validity Indices (CVIs) were calculated and any items with CVI higher than 0.79 remained.
\end{abstract}

Results: The adapted recommendations were summarized in flowcharts A to C. Two separate groups of patients who need antibiotic prophylaxis were presented in flowchart A; including those with high risk for distant-site infection (infective endocarditis and prosthetic joint infection) and those at risk for poor healing and orofacial infection (due to impaired immunologic function). Flowcharts B and C described antibiotic regimen and also the dental procedures where antibiotic prophylaxis was needed for mentioned groups. The content validity indices and the percentages of agreement between the expert panel members were considerably high.

Conclusions: A localized, clear and straight forward guideline that addresses all groups of dental patients who need antibiotic prophylaxis has been produced for Iranian general dentists.

Keywords: Antibiotic prophylaxis, Clinical practice guideline, Dental care, Infective endocarditis, Prosthetic joint

\section{Background}

Deciding about the best prescription for patients might be confusing. Clinical practice guidelines (CPGs) provide evidence based recommendations to help practitioners select the best treatment plan and the most effective drug regimen. Some international organizations and developed countries have already prepared and asserted several CPGs [1, 2]. However, different prescription patterns may be needed in other countries/communities due to drug resistance, social, cultural, economic, and/or

\footnotetext{
* Correspondence: Savadin@sums.ac.ir; savadi_naj@yahoo.com 'Department of Dental Public Health, School of Dentistry, Shiraz University of Medical Sciences, Ghasrdasht Street, Shiraz 71956-15878, Iran Full list of author information is available at the end of the article
}

promotional factors $[3,4]$. Availability, accessibility and affordability of prescribed drugs are also other factors $[5,6]$ which prevent using the same practice guideline recommendations in different countries; thus designing a localized CPG seems critical for each country.

Antibiotics are one of the most common medications prescribed by dental practitioners [7]. They are commonly prescribed for therapeutic purposes to manage oral infections [8-12]. Sometimes prescriptions are given out or recommended as prophylaxis for the prevention of distant-site infections before dental procedures $[9,13,14]$. Infective Endocarditis (IE) [15] and prosthetic joint infection (PJI) [16] are examples of medical conditions which are concerned that might occur in susceptible patients

(C) The Author(s). 2019 Open Access This article is distributed under the terms of the Creative Commons Attribution 4.0 International License (http://creativecommons.org/licenses/by/4.0/), which permits unrestricted use, distribution, and 
following dental treatment. The scientific basis for prophylaxis was to eliminate or reduce transient bacteremia caused by invasive dental procedures [17]. Patients with a compromised immune system are in the center of this kind of concerns as they may be less able to tolerate a transient bacteremia and are prone to orofacial infection following invasive dental procedures [18]. Some health scientists insist that special considerations should be paid to patients with these medical conditions. And therefore, it is important to implement strategies to prevent development of infections during dental treatments in these patients $[19,20]$.

Antibiotic prophylaxis (AP) has been considered to be safe and cost-effective. Dental practitioners have welcomed antibiotic prophylaxis regimen partly due to the fear of being blamed. However, they have also been confused about the correct prescription at the same time, as they do not deal with such patients as a routine manner.

The main potential problems of widely using AP are risk of adverse drug reactions, costs for the health-care system and risk of promoting antibiotic resistance $[15,21]$. Although the cost of antibiotic prophylaxis for an individual might be low, the potential cost for the health-care system of a country is considered high, even millions of dollar per year [21]. Furthermore, one of the biggest threats to human health in today's world is resistance to the antibiotics, according to the world health organization [22, 23]. Antibiotic resistance is defined as the ability of bacteria to change and resist against the effects of antibacterial agent [24, 25]. The loss of antibiotics' efficacy against bacteria could lead towards consumption of more expensive antibiotics in highincome countries. However, in low and middle-income countries, antibiotic resistance might increase morbidity and mortality because affordability of second-line drugs limits their use [25].

Variations in antibiotic resistance between countries can be attributed to different volumes and patterns of antibiotic consumption, whether this use is appropriate or not $[26,27]$. Due to uncertainty of medical laws and unawareness of updated guidelines, general dentists are usually confused about the indication of AP, correct dose and time of administration. They often trust to cautious practitioners' recommendations who suggest prophylaxis in any doubtful disappointing situations based on their own individual experiences [28]. Either inadequate knowledge or poor compliance with the available guidelines has been reported in many studies [29-31]. Despite widely available CPGs about AP, dentists are not always aware of the most current ones [32]. Studies have revealed that Iranian dentists have moderate level of knowledge regarding the current AP guidelines. But, they use CPGs related to other countries' organizations by their personal choice [33-35].

Therefore, there is a need to a readily accessible, problem-orientated CPG which should be matched with each community population's needs. Therefore, the aim of this study is to design and adapt a guideline about $\mathrm{AP}$, giving Iranian general dentists the recommendations on when, which and in what dosage the antibiotics should be prescribed.

\section{Methods}

This study consisted of a qualitative part and a crosssectional analytic part. It was carried out during the three main phases (Set-up phase, Adaptation phase and Finalization phase) [36] by a multidisciplinary team to oversee the adaptation process. In the first phase, a multidisciplinary team including a dental public health specialist, an oral medicine specialist, an endodontist, a periodontist, a general dentist, a pharmacologist, a $\mathrm{PhD}$ of biostatistics and an expert searcher were selected by convenience sampling and familiarized with the study. This team was served as a focus group in the qualitative phase of the study. The Adaptation phase was started through the process of searching and retrieving guidelines about AP in dentistry, assessing the guideline quality, decision making about adaptation, and preparing the draft adapted guideline. The interviews and meetings were conducted by a female dental public health $\mathrm{PhD}$ candidate who was trained and calibrated for this kind of qualitative data collection in advance. She had no relationship with any of the invited participants.

\section{Search for guidelines and other relevant documents}

Two themes were considered in advance for searching CPGs and other documents. One theme investigated AP in different group of patients including those with cardiac conditions, with prosthetic joints and with impaired immunologic functions. The other theme considered AP for adults and children, separately. Since CPGs might not be published in journals; we started the search for guidelines about AP since 2005 in guideline clearinghouses such as the National Institute for Clinical Excellence (NICE), the American Dental Association (ADA), the Royal College of Surgeons, the Scottish Dental Clinical Effectiveness Program, etc.

An additional search in a broader database such as MEDLINE, Springer, Elsevier and Cochran Library using a standardized search strategy was done for more guidelines. Following terms were used: practice guideline [Publication Type] OR guideline [Title], in combination with words related to antibiotic prophylaxis [Title] AND dental care OR dentistry OR Infective Endocarditis OR Prosthetic joint OR immunosuppression OR immunocompromised patients. Internet search engines such as 
Google and Yahoo were also used to find guidelines. A recent study indicated that available CPGs on the Internet had equal or higher quality than those published in the periodical literature [37]. A further search was also done to identify other recent and relevant documents such as recent meta-analysis or systematic reviews. These documents might be used to supplement the recommendations of retrieved guidelines.

\section{Selection between guidelines and recommendations to generate an adapted guideline}

The following characteristics of the retrieved CPGs were summarized in a table: developing organization/authors, date of publication, country/language of publication and the practice guideline's recommendations. Those CPGs which were not in English language, or were based on approvals made before 2005, and those which were outdated by a later update of the same organization were excluded.

\section{Preparation of a draft of the adapted guideline}

The focus group was asked to discuss and write their opinions about selected guidelines and recommendations. The meeting was continued until a clear conclusion was obtained. The final recommendations were attained using content analysis and coded by one calibrated coder. All transcripts returned to multidisciplinary team for comment and/or correction. The recommendations were subsequently localized based on available antibiotic forms in Iran. Antibiotics' forms and dosage were checked by pharmacologists of Food and Drug Department of Shiraz medical university. The draft of all customized recommendations and related data were prepared and summarized in the Flowcharts A to C (Additional files 1, 2, and 3). Then, all flowcharts were examined by the selected multidisciplinary team and were revised for the second time to gain the best relevant, simple and clear recommendations for general dentists.

\section{Consensus process (external peer review)}

Each dentist member of the multidisciplinary team (five people) was asked to recommend five dental specialists among Iranian university professors. Due to three duplicate names among the twenty-five introduced professors, twenty-two ones were invited for expert panel. All invited participants were informed about the study's aim, scope and process, and the interests of the interviewer, by written materials printed and sent to them. Verbal discussion over phone or in person was followed when necessary. Since two of the specialists refused to participate in the consensus process, the study was continued with twenty ones. The selected dental specialists including 2 dental public health specialists, 5 oral medicine specialists, 3 oral and maxillofacial surgeons, 3 periodontists, 3 endodontists, 1 pediatric dentist, 1 orthodontist, 1 prosthodontist and 1 restorative specialist were from four Iran universities (Tehran, Shiraz, Yazd and Bushehr University of Medical Sciences). Written informed consent was obtained from each participant in advance to their participation. All meetings were conducted in dental schools.

Three questionnaires were designed to assess the relevance and clarity of different items of flowcharts. The questionnaires consisted of 6,12 and 14 questions for flowcharts A, B and C, respectively. A 4-point ordinal scale was considered for each question to avoid a neutral midpoint [38]. Labels and the item-rating range for the four points were very relevant $=4$, relevant but need minor revision $=3$, the item need some revision $=2$, not relevant $=1$ for examining relevance and very clear $=4$, clear but need minor revision $=3$, the item need some revision $=2$, not clear $=1$ for examining clarity of each item [39].

The expert panel was asked to determine the relevance and clarity of each item by selecting one of a 4 point ordinal scale and to write any revision if needed based on their knowledge and experience. The Content Validity Index (CVI) [38, 40-42] was calculated for each item and for the flowchart as a whole, afterwards. For the Item-level-CVI (I-CVI), values range from 0 to 1 . whenever I-CVI $>0.79$, the item was considered relevant, between 0.70 and 0.79 , the item might need some revisions, and if the value was below 0.70 the item was deleted $[38,42]$. The Scale-level-CVI (S-CVI) was computed by two methods [42], one was the Universal Agreement (UA) among experts (S-CVI/UA), and the second, the Average CVI (S-CVI/Ave) [42]. A criterion of 0.80 was often used as the lower limit of acceptability for an S-CVI [40, 43]. The UA method was calculated by adding all I-CVI's equal to 1.00 divided by number of items; while the Average approach averaged the I-CVIs by summing them and dividing by the number of items.

\section{Production of the final guidance document}

In the last phase, all flowcharts were re-evaluated; any items with CVI higher than 0.79 were remained [38] and any needed revision were done. The multidisciplinary team concluded that enough data were gathered and there was no need for invitation of new participants. This last version of flowcharts presented as final guideline product for Iranian general dentists.

\section{Results}

Twenty two guidelines and systematic reviews were obtained as search results. Five guidelines were excluded and seventeen most recently updated guidelines and systematic reviews which were fully available, had structural 
soundness and met our inclusion/exclusion criteria were selected and used in this study. The results of adapted recommendations were summarized in Flowcharts A to $\mathrm{C}$ (Additional files 1, 2, and 3). Flowchart A described two distinct groups of patients who need AP. That included those with high risk for systemic/distant-site infection (IE and PJI) and those at risk for poor healing and orofacial infection (due to impaired immunologic function). Flowcharts $\mathrm{B}$ and $\mathrm{C}$ presented antibiotic regimen for groups in need of AP (described in Flowchart A) and also the dental procedures for which AP should be recommended.

Two main groups of patients who need AP were:

\section{I-patients at risk for systemic/distant-site infection}

In the recent years, the concept of AP to prevent these infections has changed considerably. Reviewing relevant literature indicated that not only antibiotic regimen for prophylaxis has become simpler and shorter, but also the number of procedures and individuals for whom AP was recommended has significantly reduced.

\section{I-I- patients with specific cardiac conditions associated with the highest risk of IE}

A 2013 Cochrane systematic review found weak evidences about the effectiveness of AP against IE in persons at risk who experienced an invasive dental procedure [44]. Due to lack of evidence either for or against AP and the extensive risks of antibiotic resistance and adverse reaction (anaphylaxis), guideline committees like the European Society of Cardiology [45] and the AHA [46] concluded that it was safer to restrict $\mathrm{AP}$ to those patients seemed to be at the highest risk (Flowchart A-Box 1). In the UK, however, AP was forbidden for all invasive procedures in 2008 according to recommendations of the NICE guideline $[14,47]$. A significant increase in cases of IE subsequently led to a subtly change in the guidance [48] which stated that "AP against IE is not recommended routinely for people undergoing dental procedures" [49]. This minor change indicated that in individual cases, AP might be appropriate; but it didn't specify the antibiotic regimen, the individuals and the dental procedures for AP $[15,48,50]$. Yet, findings of a recent study which was reported cost-effectiveness of AP especially for those at high risk clearly supported the guidelines recommending AP for high-risk individuals [51].

\section{I-II- patients with prosthetic joints at potential increased risk of PGI}

The 2014 Panel of the ADA and the AAOS proposed that in general, AP are not recommended before dental treatment for patients with prosthetic joints (PJs) due to lack of evidence for association between dental procedures and the occurrence of PJI [16]. However, they added certain exceptions to be considered in decision making for AP [52]. These exceptions included some systemic comorbid conditions that might prone patients with PJs to infection following bacteremia caused by invasive dental procedures (Flowchart A-Box 1). In these situations, yet, the mentioned guideline committees recommended that general dentists consult with the patient's physician to make better judgment for AP in patients with PJs [16].

II- patients at risk for poor healing and orofacial infection due to impaired immunologic function

There are many medical conditions associated with suppression of the immune system including some underlying diseases and medication for managing these diseases [53]. Since several documents reported the mouth as the most common source of infection and sepsis in immunosuppressed patients; AP appeared appropriate for these individuals before invasive dental procedures [18]. The National Cancer Institute suggested that AHA regimen for AP could also be prescribed for immunosuppressed patients with Absolute neutrophil count $(\mathrm{ANC})<1000$ [54]. The ANC is an important marker for quantifying a patient's severity of immunosuppression [53]. However, these recommendations are more based on medico-legal concerns and there is still weak scientific evidence for supporting the practice of routine AP before invasive dental procedures in immunocompromised patients [53].

The results of content validity tests of the mentioned flowcharts are presented in Tables 1, 2, 3. In addition to the I-CVI, the S-CVI/UA and S-CVI/Ave indices are reported in the tables. Table 1 indicates that Flowchart $\mathrm{A}$ and its items were relevant and clear. All I-CVIs were larger than the threshold value (>0.79) ranging from 0.95 to 1.00 . Moreover, the S-CVI/Ave (0.9917) and SCVI/UA (0.8333) were remarkably large.

For the 12-item Flowchart B, 99 and 100\% of experts determined items as relevant and clear, respectively. About $83 \%$ of items achieved relevance rating of 3 or 4 by all experts; while for the clarity, the universal agreement of $100 \%$ was obtained. Table 3 displayed excellent relevance and clarity for the Flowchart C items. All ICVIs were 1.00. Likewise, $100 \%$ agreement was found between all experts regarding the overall flowchart' relevance and clarity. All items of the three flowcharts had acceptable CVI values of higher than 0.79. Therefore, none of the items were eliminated. Minor revisions were made in flowchart sentences. The last versions of flowcharts which are presented here as Additional files 1, 2, and 3 were considered as final guideline products for Iranian general dentists. 
Table 1 Content validity indices for part A of the flowchart

\begin{tabular}{|c|c|c|c|}
\hline & \multirow[t]{2}{*}{ Items } & \multicolumn{2}{|l|}{$\mathrm{I}-\mathrm{CV} \mid$} \\
\hline & & Relevance & Clarity \\
\hline 1 & Assess patient's medical history & 1.00 & 1.00 \\
\hline 2 & Is the patient high risk for distant-site infection? (Refer to Box 1) & 1.00 & 1.00 \\
\hline 3 & Box 1 & 1.00 & 1.00 \\
\hline 4 & $\begin{array}{l}\text { Is the patient at risk for poor healing and systemic spread of orofacial } \\
\text { infection to impaired immunologic function? (Refer to Box 2) }\end{array}$ & 1.00 & 1.00 \\
\hline 5 & Box 2 & 0.95 & 0.95 \\
\hline \multirow[t]{3}{*}{6} & $\begin{array}{l}\text { No need for antibiotic prophylaxis } \\
\text { Do any required dental treatment }\end{array}$ & 1.00 & 1.00 \\
\hline & S-CVl/Ave & 0.9917 & 0.9917 \\
\hline & $\mathrm{S}-\mathrm{CVI} / \mathrm{UA}$ & 0.8333 & 0.8333 \\
\hline
\end{tabular}

I-CVI Item-level Content Validity Index, S-CVI/Ave Scale-level Content Validity Index, Averaging calculation method, S-CVI/UA Scale-level Content Validity Index, Universal Agreement calculation method

\section{Discussion}

The present study customized the recommendations of updated CPGs regarding AP for Iranian general dentists. Several guidelines including those from the American Heart Association (AHA) [46], the American Academy of Orthopaedic Surgeons (AAOS) [16], the ADA [16] and the American Academy of Pediatric Dentistry (AAPD) $[18,54]$ were carefully studied and used as reference guidelines. The adopted recommendations were converted to simple and practical flowcharts. The

Table 2 Content validity indices for part B of the flowchart

\begin{tabular}{|c|c|c|c|}
\hline & \multirow[t]{2}{*}{ Items } & \multicolumn{2}{|l|}{$\mathrm{I}-\mathrm{CV} \mid$} \\
\hline & & Relevance & Clarity \\
\hline 1 & $\begin{array}{l}\text { Does patient need invasive dental procedures? } \\
\text { (Refer to Box 1) }\end{array}$ & 0.95 & 1.00 \\
\hline 2 & Box 1 & 1.00 & 1.00 \\
\hline 3 & $\begin{array}{l}\text { No need for antibiotic prophylaxis } \\
\text { Do any required dental treatment }\end{array}$ & 1.00 & 1.00 \\
\hline 4 & $\begin{array}{l}\text { Need for multiple dose antibiotic prophylaxis: } \\
\text { A single high dose } 30 \text { to } 60 \text { min before dental procedure, } \\
\text { following with usual dose for } 5-7 \text { days } \\
\text { (See also Box 2) }\end{array}$ & 1.00 & 1.00 \\
\hline 5 & Does patient have history of allergy to Penicillin? & 0.95 & 1.00 \\
\hline 6 & Is patient able to take oral medication? & 1.00 & 1.00 \\
\hline 7 & $\begin{array}{l}\text { Amoxicillin } 2 \text { g orally }(4 \times 500 \text { mg Cap) } \\
\text { (For children, refer to Box } 4)\end{array}$ & 1.00 & 1.00 \\
\hline 8 & $\begin{array}{l}\text { Ampicillin } 2 \mathrm{~g} \text { IM or IV }(2 \times 1 \mathrm{~g} \text { vial) OR } \\
\text { Cefazolin or Ceftriaxone } 1 \mathrm{~g} \text { IM or IV } \\
\text { (For children, refer to Box } 4 \text { ) }\end{array}$ & 1.00 & 1.00 \\
\hline 9 & $\begin{array}{l}\text { Cephalexin } 2 \text { g orally ( } 4 \times 500 \mathrm{mg} \text { Cap) OR Clindamycin } 600 \mathrm{mg} \\
\text { orally ( } 2 \times 300 \mathrm{mg} \text { Cap) OR } \\
\text { Azithromycin } 500 \mathrm{mg} \text { orally OR } \\
\text { Clarithromycin } 500 \mathrm{mg} \text { orally } \\
\text { (For children, refer to Box 4) }\end{array}$ & 1.00 & 1.00 \\
\hline 10 & $\begin{array}{l}\text { Clindamycin } 600 \text { mg IM or IV } \\
\text { (For children, refer to Box 4) }\end{array}$ & 1.00 & 1.00 \\
\hline 11 & Box 2 & 1.00 & 1.00 \\
\hline \multirow[t]{3}{*}{12} & Box 3 & 1.00 & 1.00 \\
\hline & S-CVI/Ave & 0.9917 & 1.00 \\
\hline & S-CVI/UA & 0.8333 & 1.00 \\
\hline
\end{tabular}

I-CVI Item-level Content Validity Index, S-CVI/Ave Scale-level Content Validity Index, Averaging calculation method, S-CVI/UA Scale-level Content Validity Index, Universal Agreement calculation method 
Table 3 Content validity indices for part C of the flowchart

\begin{tabular}{|c|c|c|c|}
\hline & \multirow[t]{2}{*}{ Items } & \multicolumn{2}{|l|}{$\mathrm{I}-\mathrm{CV} \mid$} \\
\hline & & Relevance & Clarity \\
\hline 1 & $\begin{array}{l}\text { Does patient need invasive dental procedures? } \\
\text { (Refer to Box 1) }\end{array}$ & 1.00 & 1.00 \\
\hline 2 & Box 1 & 1.00 & 1.00 \\
\hline 3 & $\begin{array}{l}\text { No need for antibiotic prophylaxis } \\
\text { Do any required dental treatment }\end{array}$ & 1.00 & 1.00 \\
\hline 4 & $\begin{array}{l}\text { Need for multiple dose antibiotic prophylaxis: } \\
\text { A single high dose } 30 \text { to } 60 \mathrm{~min} \text { before dental procedure, } \\
\text { following with usual dose for 5-7 days } \\
\text { (See also Box } 2 \text { and } 3 \text { ) }\end{array}$ & 1.00 & 1.00 \\
\hline 5 & Does patient have history of allergy to Penicillin? & 1.00 & 1.00 \\
\hline 6 & Is patient able to take oral medication? & 1.00 & 1.00 \\
\hline 7 & $\begin{array}{l}\text { Amoxicillin } 2 \text { g orally }(4 \times 500 \text { mg Cap) } \\
\text { (For children, refer to Box } 4)\end{array}$ & 1.00 & 1.00 \\
\hline 8 & $\begin{array}{l}\text { Ampicillin } 2 \mathrm{~g} \text { IM or IV }(2 \times 1 \mathrm{~g} \text { vial) OR } \\
\text { Cefazolin or Ceftriaxone } 1 \mathrm{~g} \text { IM or IV } \\
\text { (For children, refer to Box } 4 \text { ) }\end{array}$ & 1.00 & 1.00 \\
\hline 9 & $\begin{array}{l}\text { Cephalexin } 2 \text { g orally (4×500mg Cap)OR } \\
\text { Clindamycin } 600 \mathrm{mg} \text { orally ( } 2 \times 300 \mathrm{mg} \text { Cap) OR } \\
\text { Azithromycin } 500 \mathrm{mg} \text { orally OR } \\
\text { Clarithromycin } 500 \mathrm{mg} \text { orally } \\
\text { (For children, refer to Box 4) }\end{array}$ & 1.00 & 1.00 \\
\hline 10 & $\begin{array}{l}\text { Clindamycin } 600 \text { mg IM or IV } \\
\text { (For children, refer to Box 4) }\end{array}$ & 1.00 & 1.00 \\
\hline 11 & $\begin{array}{l}\text { After any required invasive dental procedures: } \\
\text { Amoxicillin Cap } 500 \text { mg, q8hOR } \\
\text { Clindamycin } 300 \text { mg, q6h (for allergic patients) }\end{array}$ & & \\
\hline 12 & Box 2 & 1.00 & 1.00 \\
\hline 13 & Box 3 & 1.00 & 1.00 \\
\hline \multirow[t]{3}{*}{14} & Box 4 & 1.00 & 1.00 \\
\hline & S-CVI/Ave & 1.00 & 1.00 \\
\hline & S-CVI/UA & 1.00 & 1.00 \\
\hline
\end{tabular}

I-CVI Item-level Content Validity Index, S-CVI/Ave Scale-level Content Validity Index, Averaging calculation method, S-CVI/UA Scale-level Content Validity Index, Universal Agreement calculation method

reports from the Iranian expert panel, who evaluated relevance and clarity of the flowcharts, revealed high levels of content validity. The percentages of agreement between the expert panel members were also surprisingly high.

Although other guidelines about AP existed for specific groups, the flowchart presented in the current study would be one of the few guidelines which presented all groups who need AP together. Any dentist, a general practitioner or specialist, can simply use these flowcharts. Using Flowchart A, the two distinct groups who need AP can easily be distinguished. The dentist can easily move to Flowchart B or $\mathrm{C}$, afterwards and follow the instructions for prescribing the AP.

The present study suggested that the antibiotic regimens supported by the AHA for cardiac indications might be appropriate for preventing PJI (Flowchart B) in all susceptible patients. The underlying mechanism of bacteria spreading from mouth to prosthetic joints (PJ) was the same as IE, though the anatomy, microbiology and pathogenesis of PJI and IE were different [52]. Furthermore, when dental procedures were performed for immunocompromised patients (Flowchart C), multipledose AP involving routine single dose AP plus postoperative antibiotic regimen during the week of healing might be necessary [52-54]. In recent years, several studies reported an increased potential for developing IE $[55,56]$ and PJI $[57,58]$ in risky patients with poor oral hygiene following routine activities like toothbrushing. Thus, good oral hygiene and regular dental visits should be considered as part of the prophylactic regimen and as important as AP.

Recommended prophylactic antibiotic regimens in this study are all based on nationally available forms of antibiotics in Iran. For Amoxicillin for example, four $500 \mathrm{mg}$ capsules are stated in the flowcharts as this is the most 
available form of this antibiotic. This is while in some countries like the UK, there are ready-to-use sachets of Amoxicillin powder [48]. Furthermore, the antibiotic regimen for children based on their weight was reported in a separate box in both flowcharts.

Prophylaxis was considered reasonable for both groups of patients mentioned in Flowchart A before invasive dental procedures which manipulated the gingival tissue or the periapical region of teeth or perforated the oral mucosa $[16,18,46,50,52]$. However, in some immunocompromised patients, elective dental therapies should not be offered during severe immunosuppression phase. Furthermore, in dental emergency situations, considering the individual patient's conditions and consulting with his/her physician for required supportive medical therapies like AP would be helpful [54]. Undoubtedly, AP especially for immunocompromised patients was driven by a combination of factors including the available CPGs, long-standing belief and practice habits of dentists and physicians and also medicolegal considerations [53].

The present study introduced a national and adapted guideline regarding AP for Iranian general dental practitioners. The introduction of antibiotic prescribing guidelines in England could improve general dentists' practice in antibiotic administration and reduce the number of inappropriate prescriptions [59]. Expressing the present guidelines' recommendations in forms of flowcharts could help general dentists to get the information better, easier and faster. Introducing this national CPG and reauditing after a few years could be an initial step in implementing rational antibiotic use in Iran. Therefore, it is recommended for future studies to hold an educational program using this adapted guideline and to evaluate the feedback afterwards in order to reduce inappropriate and inaccurate antibiotic prescribing among Iranian general dental practitioners.

To move towards evidence-based practice in developing countries, it is better to emphasis on guideline adaptation and use rather than guideline development. Although guideline adaptation seemed simpler than guideline development, it was a complex timeconsuming process (12 to even 24 months) needing more resources, support and facilitation than expected. Advanced methodological skills would be required to find and to appraise high quality documents. Furthermore, one favorable feature of the present guideline was diverse composition of the multidisciplinary team and the expert panel. Although this diversity led to more difficulties in arrangements, it played an important role to participate all involved specialists of dental universities' departments in the process of guideline adaptation. The recommendations of this guideline were based on high levels of scientific evidence as well as complete consensus of the expert panel. Therefore, these recommendations, presented as flowcharts, could be confidently recommended for Iranian general dentists. It is important to remember that guideline adaptation was not an episodic activity and planning for periodically updating should be considered in all communities.

\section{Conclusion}

In the present study the recommendations retrieved from updated CPGs regarding AP, were adopted and were converted to simple flowcharts for easier and faster access of Iranian general dentists. The flowcharts contained information about two distinct groups of patients who need AP, the antibiotic regimen for both adults and children and the dental procedures for which AP should be recommended. Relevance and clarity of the overall flowcharts and their items were evaluated by an Iranian expert panel. High content validity for the flowcharts was obtained and high percentages of agreement between the experts were reported.

\section{Additional files}

Additional file 1: Our recommended flowchart for antibiotic prophylaxis for Iranian general dentists based on available antibiotics in Iran- Part A. (PDF 250 kb)

Additional file 2: Our recommended flowchart for antibiotic prophylaxis for Iranian general dentists based on available antibiotics in Iran Part B: patients at high risk for distant-site infection. (PDF 355 kb)

Additional file 3: Our recommended flowchart for antibiotic prophylaxis for Iranian general dentists based on available antibiotics in Iran Part C: patients at risk for poor healing and orofacial infection (Due to impaired immunologic function). (PDF $357 \mathrm{~kb}$ )

\section{Abbreviations}

AAOS: American Academy of Orthopaedic Surgeons; AAPD: American Academy of Pediatric Dentistry; ADA: American dental association; AHA: American Heart Association; ANC: Absolute neutrophil count; AP: Antibiotic prophylaxis; CPG: Clinical practice guideline; CVI: Content Validity Index; I-CVI: Item-level-CVI; IE: Infective endocarditis; NICE: National Institute for Clinical Excellence; PJ: Prosthetic joint; PJl: Prosthetic joint infection; S-CVI: Scale-level-CVI; S-CVI/Ave: Average CVI; S-CVI/UA: Scale-level$\mathrm{CVI} /$ Universal Agreement

\section{Acknowledgements}

The authors would like to thank Dr. Mohammadreza Khami from Oral Community Health Department of Tehran University of Medical Sciences for his contribution. The authors would like to express their gratitude to members of the multidisciplinary team and dental specialists for taking their time to participate in this study. We would also like to thank Dr. Mehrdad Vossoughi for his valuable statistical contributions.

\section{Authors' contributions}

This paper is based on a PhD thesis by NS done in School of Dentistry, Shiraz University of Medical Sciences, under the supervision of AG and advisory of $\mathrm{OB}$ and $\mathrm{HM}$. All authors were involved in making the primary concept and study design. Data collection, meetings, and manual work were done by NS. Technical advice and support was provided by AG. OB and HM helped with the development of the flowcharts and questionnaires. The first draft was prepared by NS. All authors read and approved the final manuscript. 


\section{Funding}

The Vice-chancellery for Research of Shiraz University of Medical Sciences financially supported this research covering the costs of meetings and trips.

\section{Availability of data and materials}

The data used during the current study are available from the corresponding author on reasonable request.

\section{Ethics approval and consent to participate}

The Research Ethics Committee of Shiraz University of Medical Sciences approved the study protocol (Ethical code\#IR.SUMS.REC.1395.S1125). Written informed consent was obtained from each participant.

\section{Consent for publication}

Not applicable.

\section{Competing interests}

The authors declare that they have no competing interests. The authors alone are responsible for the content and writing of the paper.

\section{Author details}

'Department of Dental Public Health, School of Dentistry, Shiraz University of Medical Sciences, Ghasrdasht Street, Shiraz 71956-15878, Iran. ${ }^{2}$ Education and Development Center, Health Human Resources Research Center, Iran University of Medical Sciences, Tehran, Iran. ${ }^{3}$ Department of Endodontics, School of Dentistry, Shiraz University of Medical Sciences, Shiraz, Iran.

\section{Received: 16 June 2019 Accepted: 3 September 2019}

\section{Published online: 07 October 2019}

\section{References}

1. Olayemi E, Asare EV, Benneh-Akwasi Kuma AA. Guidelines in lower-middle income countries. Br J Haematol. 2017;177(6):846-54.

2. Esmaeil Akbari M, Mohammadi G, Vosoogh-Moghaddam A, Rabanikhah F, Javadi $\mathrm{H}$, Rostami-Gooran $\mathrm{N}$, et al. National health guidelines in I. R of Iran, an innovative approach for developing countries. Iran J Cancer Prev. 2015; 8(2):77-83.

3. Guzmán-Álvarez R, Medeiros M, Lagunes LR, Campos-Sepúlveda A. Knowledge of drug prescription in dentistry students. Drug Healthc Patient Saf. 2012;4:55-9. https://doi.org/10.2147/DHPS.S30984.

4. Groot P, Hommersom A, Lucas P. Adaptation of clinical practice guidelines. Stud Health Technol Inform. 2008;139:121-39.

5. Karimi A, Haerizadeh M, Soleymani F, Haerizadeh M, Taheri F. Evaluation of medicine prescription pattern using World Health Organization prescribing indicators in Iran: a cross-sectional study. J Res Pharm Pract. 2014;3(2):39.

6. Cheraghali AM, Nikfar S, Behmanesh Y, Rahimi V, Habibipour F, Tirdad R, et al. Evaluation of availability, accessibility and prescribing pattern of medicines in the Islamic Republic of Iran. East Mediterr Health J. 2004;10(3):406-15.

7. Jaunay T, Dambrook P, Goss A. Antibiotic prescribing practices by south Australian general dental practitioners. Aust Dent J. 2000;45(3):179-86.

8. Drug Prescribing For Dentistry. Dental Clinical Guidance. Third Edition [Internet]. The Scottish Dental Clinical Effectiveness Programme. 2016. Available from: http://www.sdcep.org.uk/published-guidance/drug-prescribing/. .

9. Poveda Roda R, Bagan JV, Sanchis Bielsa JM, Carbonell PE. Antibiotic use in dental practice. A review. Med Oral Patol Oral Cir Bucal. 2007;12(3):E186-92.

10. Swift JQ, Gulden WS. Antibiotic therapy-managing odontogenic infections Dent Clin N Am. 2002;46(4):623-33.

11. Caviglia I, Techera A, García G. Antimicrobial therapies for odontogenic infections in children and adolescents. Literature review and clinical recomendations. J Oral Res. 2013;3(1):50-6.

12. Bassiur J, Boyd B, Burrrel K, Byrne E, Fricton J, Fugh-Berman A, et al. Guide to dental therapeutics. 5th ed. American Dental Association and Physicians' Desk Reference Inc: USA (Chicago); 2009.

13. Wilson W, Taubert KA, Gewitz M, Lockhart PB, Baddour LM, Levison M, et al. Prevention of infective endocarditis: guidelines from the American Heart Association: a guideline from the American Heart Association Rheumatic Fever, Endocarditis, and Kawasaki Disease Committee, Council on Cardiovascular Disease in the Young, and the Council on Clinical Cardiology, Council on Cardiovascular Surgery and Anesthesia, and the Quality of Care and Outcomes Research Interdisciplinary Working Group. Circulation. 2007;116(15):1736-54.
14. Stokes T, Richey R, Wrayon D. Prophylaxis against infective endocarditis: summary of NICE guidance. Heart. 2008;94(7):930-1.

15. Thornhill MH, Dayer M, Lockhart PB, Prendergast B. Antibiotic prophylaxis of infective endocarditis. Curr Infect Dis Rep. 2017;19(2):9. https://doi.org/10. 1007/s11908-017-0564-y.

16. Sollecito TP, Abt E, Lockhart PB, Truelove E, Paumier TM, Tracy SL, et al. The use of prophylactic antibiotics prior to dental procedures in patients with prosthetic joints: evidence-based clinical practice guideline for dental practitioners - a report of the American Dental Association Council on Scientific Affairs. J Am Dent Assoc. 2015;146(1):11-6. e8.

17. Daly CG. Antibiotic prophylaxis for dental procedures. Aust Prescr. 2017; 40(5):184-8.

18. Guideline on antibiotic prophylaxis for dental patients at risk for infection. American Academy of Pediatric Dentistry. Pediatr Dent. 2016;38(6):328-33.

19. Cahill TJ, Prendergast BD. Infective endocarditis. Lancet. 2016;387(10021): 882-93.

20. Hoen B, Duval X. Clinical practice. Infective endocarditis. N Engl J Med. 2013; 368(15):1425-33.

21. Lockhart PB, Blizzard J, Maslow AL, Brennan MT, Sasser H, Carew J. Drug cost implications for antibiotic prophylaxis for dental procedures. Oral Surg Oral Med Oral Pathol Oral Radiol. 2013;115(3):345-53.

22. World Health Organization. Global action plan on antimicrobial resistance. 2015. Available from: www.who.int/antimicrobial-resistance/publications/ global-action-plan/en/. Accessed May 2015.

23. Conly J. Antimicrobial resistance: revisiting the "tragedy of the commons". Bull World Health Organ. 2010;88(11):805-6.

24. Laxminarayan R, Matsoso P, Pant S, Brower C, Røttingen J-A, Klugman K, et al. Access to effective antimicrobials: a worldwide challenge. Lancet. 2016;387(10014):168-75.

25. Laxminarayan R, Duse A, Wattal C, Zaidi AK, Wertheim HF, Sumpradit N, et al. Antibiotic resistance-the need for global solutions. Lancet Infect Dis. 2013;13(12):1057-98.

26. Laxminarayan $\mathrm{R}$, Heymann DL. Challenges of drug resistance in the developing world. BMJ. 2012;344:e1567. https://doi.org/10.1136/bmj.e1567.

27. Goossens H, Ferech M, Vander Stichele R, Elseviers M, Group EP. Outpatient antibiotic use in Europe and association with resistance: a cross-national database study. Lancet. 2005;365(9459):579-87.

28. Tong DC, Rothwell BR. Antibiotic prophylaxis in dentistry: a review and practice recommendations. J Am Dent Assoc. 2000;131(3):366-74.

29. Boyle N, Gallagher C, Sleeman D. Antibiotic prophylaxis for bacterial endocarditis--a study of knowledge and application of guidelines among dentists and cardiologists. J Ir Dent Assoc. 2006;51(5):232-7.

30. Adeyemo WL, Oderinu OH, Olojede AC, Ayodele AO, Fashina AA. Nigerian dentists' knowledge of the current guidelines for preventing infective endocarditis. Community Dent Health. 2011;28(2):178-81.

31. Nakano K, Ooshima T. Common knowledge regarding prevention of infective endocarditis among general dentists in Japan. J Cardiol. 2011:57(1): 123-30.

32. Lauber $\mathrm{C}$, Lalh SS, Grace M, Smith MH, MacDougall K, West $P$, et al. Antibiotic prophylaxis practices in dentistry: a survey of dentists and physicians. J Can Dent Assoc. 2007;73(3):245

33. Sadr S, Vakili Nezhad M, Ansari FS. Knowledge of dentists towards antibiotic prophylaxis in Bandar Abbas 2015. J Res Med Dent Sci. 2018;6(1):157-60.

34. Ghaderi F, Oshagh M, Dehghani R, Hasanshahi R. Awareness of Iranian's general dentists regarding the latest prophylaxis guideline for prevention of infective endocarditis. J Dent (Shiraz). 2013;14(1):6-12.

35. Eskandari A, Abolfazli N, Lafzi A. Endocarditis prophylaxis in cardiac patients: knowledge among general dental practitioners in Tabriz. J Dent Res Dent Clin Dent Prospects. 2008;2(1):15-9. https://doi.org/10.5681/joddd.2008.003.

36. The ADAPTE Collaboration. The ADAPTE Process: Resource Toolkit for guideline adaptation. Version 2.0. 2009. Available from: https://www.g-i-n. net. Acessed Feb 2010.

37. Fervers B, Burgers JS, Haugh MC, Latreille J, Mlika-Cabanne N, Paquet L, et al. Adaptation of clinical guidelines: literature review and proposition for a framework and procedure. Int J Qual Health Care. 2006;18(3):167-76.

38. Lynn MR. Determination and quantification of content validity. Nurs Res. 1986;35(6):382-5.

39. Yaghmaie F. Content validity and its estimation. J Med Educ. 2003;3(1):25-7. https://doi.org/10.22037/jme.v3i1.870.

40. Polit DF, Beck CT, Owen SV. Is the CVI an acceptable indicator of content validity?Aprraisal and recommendations. Res Nurs Health. 2007;30(4):459-67. 
41. Shultz KS, Whitney DJ. Measurement theory in action: case studies and exercises. California: Sage Publications; 2005. Available from: https://epdf. tips/measurement-theory-in-action-case-studies-and-exercises.html

42. Polit DF, Beck CT. The content validity index: are you sure you know what's being reported? Critique and recommendations. Res Nurs Health. 2006; 29(5):489-97.

43. Davis LL. Instrument review: getting the most from a panel of experts. Appl Nurs Res. 1992;5(4):194-7.

44. Glenny AM, Oliver R, Roberts GJ, Hooper L, Worthington HV. Antibiotics for the prophylaxis of bacterial endocarditis in dentistry. Cochrane Database Syst Rev. 2013;10:CD003813. https://doi.org/10.1002/14651858. CD003813.pub4.

45. Habib G, Lancellotti P, Antunes MJ, Bongiorni MG, Casalta JP, Del Zotti F, et al. 2015 ESC guidelines for the management of infective endocarditis: the task force for the Management of Infective Endocarditis of the European Society of Cardiology (ESC) endorsed by: European Association for CardioThoracic Surgery (EACTS), the European Association of Nuclear Medicine (EANM). Eur Heart J. 2015;36(44):3075-128.

46. Nishimura RA, Otto CM, Bonow RO, Carabello BA, Erwin JP, Fleisher LA, et al. 2017 AHA/ACC focused update of the 2014 AHA/ACC guideline for the management of patients with valvular heart disease: a report of the American College of Cardiology/American Heart Association task force on clinical practice guidelines. Circulation. 2017;135(25):e1159-95.

47. National Institute for Health and Clinical Excellence (NICE). Prophylaxis against infective endocarditis: antimicrobial prophylaxis against infective endocarditis in adults and children undergoing interventional procedures. 2008. NICE Clinical Guideline No 64. Available from: www.nice.org.uk/CG064. Acessed Mar 2008.

48. Thornhill MH, Dayer M, Lockhart PB, McGurk M, Shanson D, Prendergast $\mathrm{B}$, et al. A change in the NICE guidelines on antibiotic prophylaxis. $\mathrm{Br}$ Dent J. 2016;221(3):112-4

49. National Institute for Health and Care Excellence (NICE). Prophylaxis against infective endocarditis: antimicrobial prophylaxis against infective endocarditis in adults and children undergoing interventional procedures. NICE Clinical Guideline No 64. Updated 2016. Available from: https:/www. nice.org.uk/guidance/cg64/chapter/Recommendations. Accessed July 2016.

50. Thornhill MH, Dayer M, Lockhart PB, McGurk M, Shanson D, Prendergast B, et al. Guidelines on prophylaxis to prevent infective endocarditis. Br Dent J. 2016;220(2):51-6.

51. Franklin M, Wailoo A, Dayer MJ, Jones S, Prendergast B, Baddour LM, et al. The cost-effectiveness of antibiotic prophylaxis for patients at risk of infective endocarditis. Circulation. 2016;134(20):1568-78.

52. Little J, Miller $C$, Rhodus N. Little and Falace's dental management of the medically compromised patient. 9th ed. Riverport Lane: Elsevier; 2018

53. Donaldson M, Goodchild J, Wrobel M. Pharmacotherapy. Burket's oral medicine. 12th ed. Shelton: PMPH-USA: 2015.

54. Guideline on dental management of pediatric patients receiving chemotherapy, hematopoietic cell transplantation, and/or radiation therapy. American Academy of pediatric Dentistry. Pediatr Dent. 2016;38(6):334-42.

55. Dhotre SV, Davane MS, Nagoba BS. Periodontitis, bacteremia and infective endocarditis: a review study. Arch Pediatr Infect Dis. 2017. https://doi.org/10. 5812/pedinfect.41067.

56. Lockhart PB, Brennan MT, Thornhill M, Michalowicz BS, Noll J, BahraniMougeot FK, et al. Poor oral hygiene as a risk factor for infective endocarditis-related bacteremia. J Am Dent Assoc. 2009;140(10):1238-44.

57. Legout $L$, Beltrand E, Migaud H, Senneville E. Antibiotic prophylaxis to reduce the risk of joint implant contamination during dental surgery seems unnecessary. Orthop Traumatol Surg Res. 2012;98(8):910-4.

58. McNally CM, Visvanathan R, Liberali S, Adams RJ. Antibiotic prophylaxis for dental treatment after prosthetic joint replacement: exploring the orthopaedic surgeon's opinion. Arthroplast Today. 2016;2(3):123-6.

59. Palmer NA, Dailey YM, Martin MV. Can audit improve antibiotic prescribing in general dental practice? Br Dent J. 2001;191(5):253-5.

\section{Publisher's Note}

Springer Nature remains neutral with regard to jurisdictional claims in published maps and institutional affiliations.

\section{Ready to submit your research? Choose BMC and benefit from:}

- fast, convenient online submission

- thorough peer review by experienced researchers in your field

- rapid publication on acceptance

- support for research data, including large and complex data types

- gold Open Access which fosters wider collaboration and increased citations

- maximum visibility for your research: over $100 \mathrm{M}$ website views per year

At BMC, research is always in progress.

Learn more biomedcentral.com/submissions 